The Effect of Protestantism on Education before the Industrialization: Evidence from 1816 Prussia

Sascha O. Becker

Ludger Woessmann

Stirling Economics Discussion Paper 2010-01

January 2010

Online at http://www.economics.stir.ac.uk 


\section{The Effect of Protestantism on Education before the Industrialization: Evidence from 1816 Prussia $^{*}$}

\author{
Sascha O. Becker ${ }^{\dagger}$ \\ U Stirling, Ifo, CESifo and IZA
}

\author{
Ludger Woessmann ${ }^{\ddagger}$ \\ U Munich, Ifo, CESifo and IZA
}

This paper uses recently discovered data on nearly 300 Prussian counties in 1816 to show that Protestantism led to more schools and higher school enrollment already before the industrialization. This evidence supports the human capital theory of Protestant economic history of Becker and Woessmann (2009), where Protestantism first led to better education, which in turn facilitated industrial development. It rules out that the existing end-of- $19^{\text {th }}$-century evidence can be explained by a Weberian explanation, where a Protestant work ethic first led to industrialization which then increased the demand for education.

Keywords: Education, Protestantism, Pre-Industrialization

JEL classification: I21, N33, Z12

\footnotetext{
* Capable research assistance by Erik Hornung and Clemens König is gratefully acknowledged.

† Division of Economics, Stirling Management School, University of Stirling, Stirling FK9 4LA, United Kingdom; sascha.becker@stir.ac.uk.

${ }^{\ddagger}$ Department of Economics, University of Munich and Ifo Institute for Economic Research, Poschingerstr. 5, 81679 Munich, Germany; woessmann@ifo.de.
} 


\section{Introduction}

The causes of the economic lead of Protestant regions over Catholic regions has fascinated researchers ever since Max Weber's (1904/2001) seminal contribution, which suggested that a specific Protestant ethic was instrumental in facilitating capitalist industrialization. Recently, Becker and Woessmann (2009) suggested that Protestants' education, rather than their work ethic, may have been the dominating cause. In the 1520s, Martin Luther preached that Christians themselves should be able to read God's Word as contained in the Bible. Luther also explicitly urged rulers to build schools and parents to send their children to school. The superiority of Protestant education is shown with Prussian data from 1871, when industrialization was substantially advanced. ${ }^{1}$ However, recent unified growth theories like Galor and Moav (2006) stress that the process of industrialization might itself have increased the demand for education by enhancing the importance of human capital in production, which generated incentives for capitalists to support the provision of public education for the masses. This raises another possible explanation for the evidence from after the Industrial Revolution: In accordance with Weber's argument, a Protestant work ethic might have facilitated industrialization, which in turn increased the demand for education:

$$
\text { Protestantism } \Rightarrow \text { industrialization } \Rightarrow \text { education }
$$

Then, the higher education of Protestants in the 1870s might have been the consequence rather than the cause of industrialization.

In this paper, we test this possibility by providing evidence on the effect of Protestantism on education as early as 1816, using newly discovered data for 293 Prussian counties. 1816 is well before the start of industrialization in Prussia, which is generally placed in the mid-1830s (e.g., Tilly 1996). ${ }^{2}$ We find a significant effect of the share of Protestants in a county both on the number of primary schools and on primary-school enrollment in 1816, ruling out the possibility that the better education of Protestant regions was just a consequence of industrialization. This result strengthens the explanation that better education lies at the root of Protestant economic development during the times of industrialization:

1 See Becker and Woessmann (2009), who also provide evidence on a positive association between Protestantism and education across 22 countries in 1900 and for Germany in 1997. Goldin and Katz (2009) provide similar evidence for the United States in 1910-1938.

${ }^{2}$ In Prussia, the new industrial technologies clearly did not emerge in any notable extent before the Napoleonic rule of 1806-1813, which brought fundamental institutional reforms that were a pre-requisite for structural change. 


$$
\text { Protestantism } \Rightarrow \text { education } \Rightarrow \text { industrialization }
$$

To rule out issues of reverse causation and omitted variables in the Protestantism-education nexus and identify a causal effect of Protestantism, we exploit the fact that in Luther's times, Protestantism spread roughly in circles around his city, Wittenberg. This allows us to obtain exogenous variation in Protestantism by instrumenting the share of Protestants in a county by its distance to Wittenberg in an instrumental-variable (IV) specification.

\section{County-Level Data for 1816 Prussia}

The Prussian Statistical Office conducted the first full-scale Population Census in 1816 (Mützell 1825). This is the earliest point in time which lends itself to a micro-regional analysis of education and religion. In contrast to many British studies on education during industrialization which had to rely on non-representative samples, the census provides representative data from a full national population count.

Our data refer to 293 counties covering the whole of Prussia in 1816 (except the 11 counties of the Cologne district which lacked education data). Basic descriptive statistics are provided in Table A1 in the Appendix. The average share of Protestants is $61 \%$, varying from $0 \%$ to $100 \%$ across counties. This stark distinction between all-Protestant and all-Catholic counties in Prussia (see also Figure 1) provides the interesting denominational variation within the framework of a single country that enables the analysis of this paper.

We use two indicators of schooling: the number of public primary schools per 1,000 inhabitants in the county and the enrollment rate of school-age children. The number of public primary schools varies widely from less than 0.1 to nearly 5 primary schools per 1,000 inhabitants. Interestingly, the counties with the five highest values of schools per inhabitant all have a Protestant majority, whereas the counties with the five lowest values all have a Catholic majority. The enrollment rate is computed as the number of pupils enrolled in public primary schools divided by the number of children in the age group 6-14. ${ }^{3}$ The average enrollment rate in the 181 Protestant-majority counties is $67.2 \%$, whereas it is only $48.5 \%$ in the 112 Catholicmajority counties.

\footnotetext{
${ }^{3}$ The age group 6-14 is the relevant school age in Prussian primary schools, and is computed by adding one quarter of the children in the 0-7 age group to the number of children in the 8-14 group, as available in our data. Results are robust when we just use the number of children in the age group 8-14 as the denominator.
} 


\section{Results on the Effect of Protestantism on Education in 1816 Prussia Primary School Supply}

Table 1 analyzes the relationship between Protestantism and school supply in a regression framework. In a bivariate regression of the number of primary schools per 1,000 inhabitants on the fraction of Protestants, going from an all-Catholic county to an all-Protestant county yields one more primary school per 1,000 inhabitants, a sizeable effect. Adding geographical controls (latitude, longitude, and their interaction), the share of the population living in towns, and demographic controls (the share of the population younger than 15 years and older than 60 years) does not affect the qualitative result on Protestantism. The location and urbanization variables control for potentially different school supply patterns across geographic areas. The demographic controls capture relative population sizes of past and current generations that might influence the number of schools built.

Another reason for school supply to vary across counties may be the stage of development. Richer regions may have constructed more schools than poorer regions. Direct income measures are not available in the 1816 Prussian Census data. However, natural proxies are variables measuring agricultural productivity, in particular after controlling for the share of people living in towns. We transform the following livestock counts to per-capita numbers: the number of horses, foals, bulls, oxen, cows, young cattle, sheep, and goats. Column (3) uses only the number of horses and bulls per capita, but results are very similar when using all agricultural variables (with the other agricultural variables being statistically insignificant). Further indicators of economic development are the number of looms per capita, the share of farm laborers in the total population, and tonnage of transport ships. Note that controlling for such indicators of economic development may lead to an underestimation of the Protestantism effect to the extent that their higher education might have given Protestants an economic advantage already in pre-industrial times. But again, the coefficient on the share of Protestants is hardly changed.

\section{Instrumental-Variable Specification with Distance to Wittenberg as Instrument}

Because the conversion to Protestantism may be reversely caused by education or correlated with omitted variables that are themselves correlated with education, we need exogenous variation in Protestantism to obtain causal identification. Most of the denominational variation in

$19^{\text {th }}$-century Prussia can be traced back to choices of local rulers during the Reformation in $16^{\text {th }}$ 
and early $17^{\text {th }}$ centuries, mostly motivated by religious conviction and power politics. Following the principle "cuius region, eius religio" (whose rule, his religion) adopted at the Imperial Diet in 1555, citizens had to follow the religious choice of their rulers. Luther and his fellow reformers implemented Reformation ideals in their purest form in Electoral Saxony, with Wittenberg at its heart. With increasing distance to Wittenberg, rulers were less likely to adopt Protestantism. Figure 1 displays the roughly concentric spread of Protestantism within Prussia.

We thus use distance to Wittenberg as an instrumental variable for Protestantism. Becker and Woessmann (2009) provide evidence in support of the validity of this instrument: It is orthogonal to pre-Reformation economic and educational development as proxied by being a free imperial or Hanseatic city, urban population density, city size, existence and year of foundation of universities and schools, and density of monasteries as centers of learnedness. Consequently, the geographically concentric pattern of the dispersion of the Reformation provides a means to obtain variation in Protestantism exogenous to economic and educational considerations.

As is evident from the F-statistic of the instrument in the first stage, distance to Wittenberg is a strong instrument for the share of Protestants in a county (columns (4)-(6)). Each $100 \mathrm{~km}$ distance to Wittenberg is associated with a Protestant share that is 12-18 percentage points lower. The second stage uses only that part of the Protestant share that is due to distance to Wittenberg to predict primary school supply (columns (7)-(9)). The positive effect of Protestantism on primary school supply is robust in the IV specification, showing a difference of 0.8 to 1.4 schools per 1,000 inhabitants between an all-Protestant and an all-Catholic county.

\section{Primary School Enrollment}

Similar results hold when using school enrollment as the dependent variable in Table 2. In a bivariate regression of the primary school enrollment rate on the fraction of Protestants, allProtestant areas have a substantial 20.4 percentage points higher enrollment rate than allCatholic areas. Again, the result is confirmed when adding geographical controls and indicators of economic development, as well as in the IV specification.

An empirical question related to the human capital model is whether school enrollment is mostly demand-driven or supply-driven, i.e. whether higher enrollment is partly explained by better school supply in Protestant areas. To probe this point, we include the number of primary schools per 1,000 inhabitants as a control. As columns (4) and (8) reveal, both the number of 
schools and Protestantism enter significantly, suggesting that Protestants have a higher tendency to enroll their children in school even for given school supply. The reduction in the point estimate on Protestantism suggests that supply and demand contribute roughly half and half to the total effect of Protestantism on school enrollment.

Finally, we have separate data on school enrollment in 156 "large and medium-sized" towns, the smallest of which had roughly 2,500 inhabitants. While these towns are also contained in the county averages of the county-level data, the town data provide additional insights into the robustness of our results. As one might expect in urban areas, we do not find an effect of Protestantism on the supply of schools (not reported). However, as column (9) shows, the enrollment rate in Protestant towns is again significantly higher than in Catholic towns, even after controlling for town-specific indicators of economic development.

\section{Conclusion}

We show that Protestantism had a positive effect on school supply and educational enrollment across 293 Prussian counties even before the industrialization, in 1816. Based on IV estimates, school enrollment in all-Protestant counties was about 25 percentage points higher than in all-Catholic counties. This rejects the possibility that the better education of Protestant areas at the end of the $19^{\text {th }}$ century was just a consequence of increased demand for education due to industrialization. The finding strengthens a human capital interpretation of Protestant economic history where Luther's urge to read the Bible created human capital that then facilitated industrial development.

\section{References}

Becker, Sascha O., Ludger Woessmann (2009). Was Weber Wrong? A Human Capital Theory of Protestant Economic History. Quarterly Journal of Economics 124 (2): 531-596.

Galor, Oded, Omer Moav (2006). Das Human-Kapital: A Theory of the Demise of the Class Structure. Review of Economic Studies 73 (1): 85-117.

Goldin, Claudia, Lawrence F. Katz (2009). Why the United States Led in Education: Lessons from Secondary School Expansion, 1910 to 1940. In: David Eltis, Frank D. Lewis (eds.), Human Capital and Institutions: A Long-Run View, pp.143-178. New York: Cambridge University Press.

Mützell, Alexander A. (1825). Neues Topographisch-statistisch-geographisches Wörterbuch des Preussischen Staats. Halle: Karl August Kümmel.

Tilly, Richard H. (1996). German Industrialization. In: Mikuláš Teich, Roy Porter (eds.), The Industrial Revolution in National Context: Europe and the USA, pp. 95-125. Cambridge: Cambridge University Press.

Weber, Max (1904). Die protestantische Ethik und der „Geist“ des Kapitalismus. Archiv für Sozialwissenschaft und Sozialpolitik 20: 1-54. [The Protestant Ethic and the Spirit of Capitalism, London: Routledge Classics, 2001.] 
Figure 1: Protestantism in Prussia in 1816

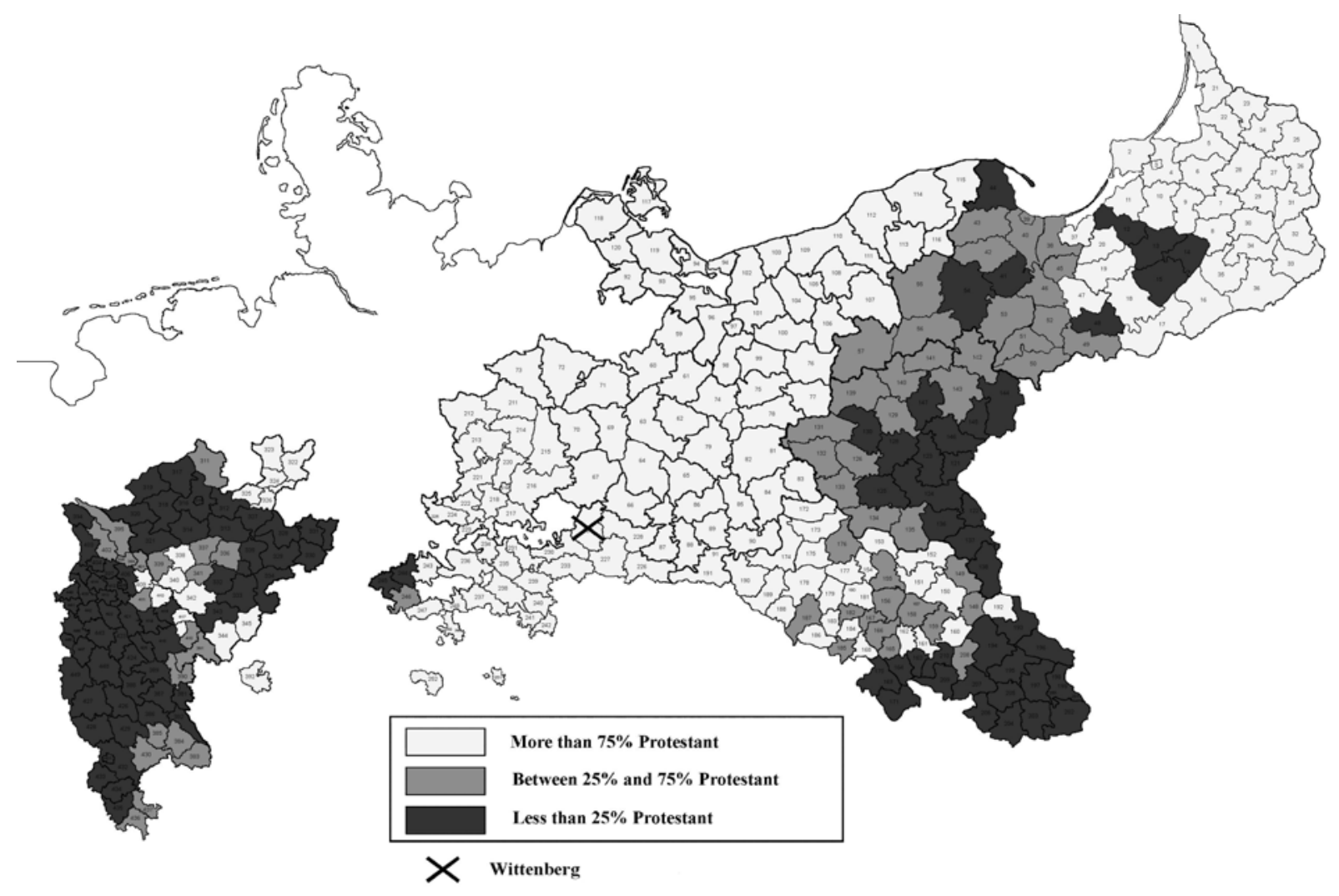




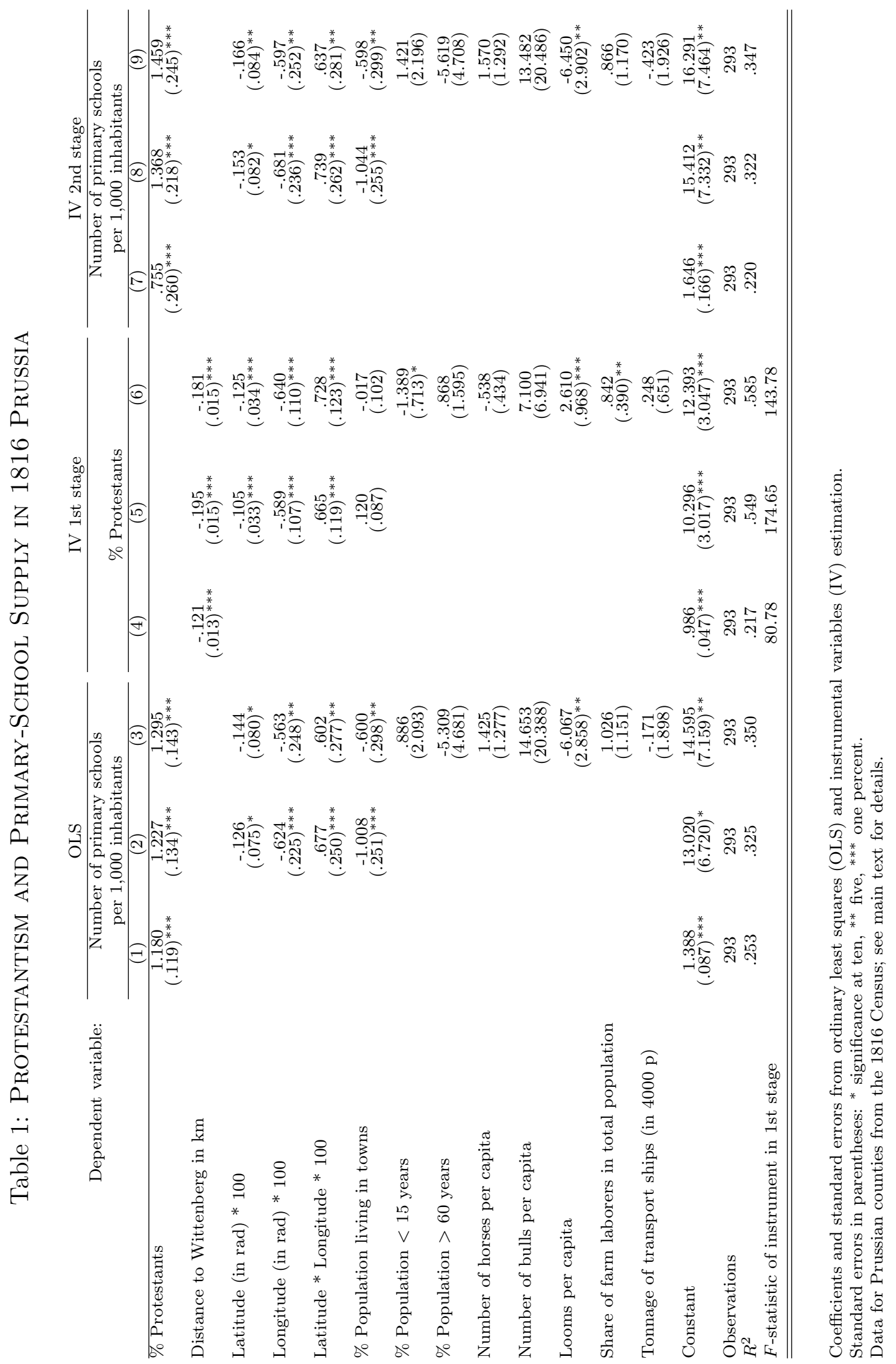




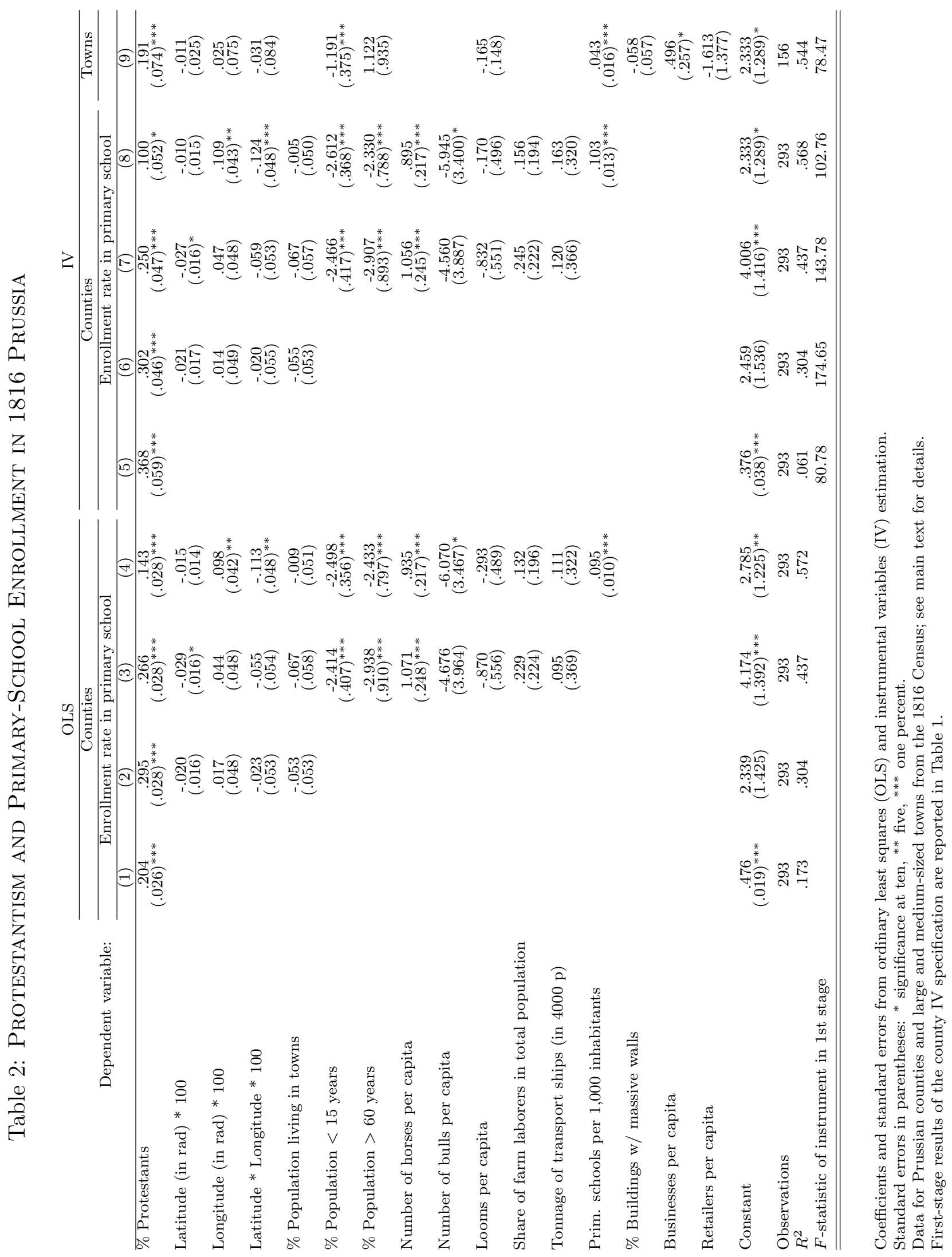


Table A.1: Descriptive Statistics: Prussian Counties, 1816

\begin{tabular}{lrrrr} 
& Mean & StdDev & Min & Max \\
\cline { 2 - 5 } & \multicolumn{1}{c}{$(1)$} & $(2)$ & $(3)$ & $(4)$ \\
\hline Panel A: County totals & & & & \\
\% Protestants & 60.93 & 40.26 & .00 & 99.96 \\
Prim. schools per 1,000 inhabitants & 2.11 & .94 & .08 & 4.86 \\
School enrollment rate & 60.02 & 19.72 & 2.15 & 110.24 \\
Distance to Wittenberg in km & 311.45 & 155.04 & .00 & 729.62 \\
Latitude (in rad) * 100 & 90.62 & 2.27 & 85.93 & 97.24 \\
Longitude (in rad) * 100 & 22.68 & 8.05 & 10.52 & 39.40 \\
\% Population living in towns & 11.18 & 18.71 & .00 & 100.00 \\
\% Population < 15 years & 36.09 & 2.90 & 21.41 & 45.57 \\
\% Population > 60 years & 6.58 & 1.35 & 3.89 & 10.68 \\
Number of horses per capita & .10 & .06 & .006 & .35 \\
Number of bulls per capita & .005 & .003 & .0000245 & .03 \\
Looms per capita & .006 & .02 & .00 & .24 \\
Share of farm laborers in total population & .05 & .05 & .00 & .24 \\
Tonnage of transport ships (in 4000 p) & .007 & .03 & .00 & .31 \\
\hline & & & & \\
Panel B: Large and medium-sized towns & & & & \\
\% Protestants & 69.53 & 35.39 & .11 & 100.00 \\
Prim. schools per 1,000 inhabitants & 1.55 & .86 & .32 & 5.19 \\
School enrollment rate & 57.87 & 19.11 & 5.80 & 124.22 \\
Distance to Wittenberg in km & 290.24 & 151.43 & 30.15 & 708.50 \\
\% Population < 15 years & 33.16 & 4.27 & 23.03 & 52.83 \\
\% Population > 60 years & 7.21 & 1.61 & 3.75 & 14.72 \\
Latitude (in rad) * 100 & 90.77 & 2.21 & 85.93 & 97.24 \\
Longitude (in rad) * 100 & 22.37 & 7.53 & 10.52 & 38.75 \\
Looms per capita & .03 & .09 & .00 & 1.04 \\
\% Buildings w massive walls & 23.85 & 27.88 & .00 & 100.00 \\
Businesses per capita & .19 & .06 & .07 & .45 \\
Retailers per capita & .02 & .01 & .003 & .06 \\
\hline
\end{tabular}

Number of observations: 293 counties in panel A; 156 towns in panel B.

Data for Prussian counties and large and medium-sized towns from the 1816 Census; see main text for details. 